\title{
Influência do sombreamento na produção de biomassa, óleo essencial e quantidade de tricomas glandulares em cidrão (Lippia citriodora Lam.)
}

\author{
Paula Alessandra Gomes ${ }^{1 *}$ \\ Manoel Ferreira de Souza ${ }^{2}$ \\ Ismail Teodoro de Souza Júnior ${ }^{2}$ \\ Wellington Geraldo Oliveira Carvalho Junior ${ }^{2}$ \\ Lourdes Silva de Figueiredo ${ }^{2}$ \\ Ernane Ronie Martins ${ }^{2}$ \\ ${ }^{1}$ Universidade Estadual do Norte Fluminense, \\ Av. Alberto Lamego, 2000, CEP 28013-602, Campos dos Goytacazes - RJ, Brasil \\ ${ }^{2}$ Instituto de Ciências Agrárias \\ Universidade Federal de Minas Gerais, Belo Horizonte - MG, Brasil \\ *Autor para correspondência \\ paulaagronomia@yahoo.com.br
}

\section{Resumo}

O objetivo do estudo foi verificar o efeito do sombreamento na produção de óleo essencial, biomassa e quantidade de tricomas glandulares em cidrão (Lippia citriodora Lam.) no Norte de Minas Gerais. O delineamento experimental foi inteiramente casualizado, com quatro tratamentos e cinco repetições. Os tratamentos consistiram em quatro níveis de radiação fotossinteticamente ativa (RFA) utilizando telas tipo sombrite que permitem a passagem de 25, 50,70\% de luz e a pleno sol (controle). Foram determinadas as variáveis: matéria seca da raiz, matéria seca da parte aérea, número de flores, matéria seca total, relação raiz/parte aérea, produção de óleo, teor de óleo essencial e quantidade de tricomas glandulares. Foram observadas diferenças estatisticamente significativas para massa seca da raiz, massa seca da parte aérea, número de flores, matéria seca total, razão raiz/ parte aérea, produção de óleo e quantidade de tricomas, todavia o mesmo não ocorreu para o teor de óleo. Os resultados evidenciaram que a pleno sol houve uma maior produção de biomassa que nos demais tratamentos e no sombreamento de $70 \%$ o número de tricomas foi maior. O teor de óleo não sofreu nenhuma alteração em relação aos tratamentos.

Unitermos: plantas medicinais, plasticidade, radiação luminosa

\section{Abstract}

Influence of shade on the biomass and essential oil production of Lippia citriodora (Lam.), Brazil. This study aimed to evaluate the effect of shading on the production of essential oil and biomass in Lippia citriodora (Lam.) - known as cidrão - in the north of Minas Gerais, Brazil. The experimental design was 
completely randomized, with four treatments and five repetitions. The treatments consisted of four levels of photosynthetically-active radiation (PAR) using "Sombrite" black shade netting of 25, 50, 70\% of light and full sunlight as the control. The variables root dryness, shoot dryness, number of flowers, total dry weight, root/ shoot ratio, and production and content of essential oil were analyzed. Statistically significant differences were observed for the root and shoot dry masses and total dry mass, number of flowers, total dry weight, root/shoot ratio, oil production and trichome number, but not for the oil content. The results showed that at full sunlight the biomass production and trichome number of cidrão were altered, but that the content of essential oil was unaffected.

Key words: medicinal plants, plasticity, radiation

\section{Introdução}

O estabelecimento de práticas que visem o cultivo, manejo sustentável, a produção e o uso de plantas medicinais vêm crescendo em todo o mundo. $\mathrm{Na}$ verdade, os produtos naturais nunca deixaram de ser parte da composição de muitos medicamentos, e ainda hoje esses produtos, incluindo seus derivados e análogos, representam quase $50 \%$ de todas as drogas terapêuticas em uso clínico, das quais as plantas superiores são aproximadamente $20 \%$ do total (Perecin et al., 2002).

O cidrão (Lippia citriodora Lam.) é uma espécie da família Verbenaceae, nativa da América do Sul, provavelmente do Chile, Argentina, Peru e cultivada no Sul do Brasil (Simões et al., 1998). Possui porte arbustivo, caule ereto e muito ramificado, podendo alcançar de 2-3m de altura, folhas simples, cartáceas, de margens geralmente serreadas na porção apical, verticiladas, em número de três ou quatro por nó, de $8-12 \mathrm{~cm}$ de comprimento (Lorenzi e Matos, 2002). Flores são brancas ou levemente rosadas, dispostas em inflorescências paniculadas terminais (Simões et al., 1998), sendo muito apreciada por possuir um aroma cítrico, além de ser utilizada em licores, perfumes, na culinária, como medicinal e ornamental. É usada como aromática, depressora do sistema nervoso central, cardiotônica, descongestionante, digestiva, (Teske e Trinttini, 1997). Seu óleo essencial já foi muito popular em perfumaria, porém seu uso diminuiu nos últimos anos após a evidência de que pode sensibilizar a pele à ação do sol. Outras características importantes do óleo essencial são suas propriedades bactericidas e inseticidas (Chopra et al., 1986). A produção dessa planta pode ser uma alternativa para pequenos produtores da região, já que o mercado encontra-se em expansão e recebendo incentivos que visam à produção sustentável.

Fatores do meio ambiente como luz, temperatura e água influenciam diretamente o desenvolvimento vegetativo das plantas. A falta de um desses componentes ocasiona a redução do vigor da planta e limita seu desenvolvimento. A disponibilidade de luz para as plantas pode interferir no seu desenvolvimento vegetativo. Espécies podem ser agrupadas em dois grandes grupos: pioneiras (heliófitas) que requerem radiação solar direta para a germinação e o crescimento satisfatório de suas plântulas, e clímax (umbrófilas), que são tolerantes ao sombreamento inicial, podendo germinar, sobreviver e desenvolver-se sob dossel fechado, com pouca luz (Ramos et al., 2004). Quanto à exposição solar, o cidrão necessita de ambiente luminoso ou semi-sombreado. Uma boa iluminação influencia na síntese de óleo essencial. Um local pouco iluminado favorece o tamanho das folhas, mas com poucos princípios ativos (Rivas, 2003). Como forma de adaptação às condições adversas, as plantas têm como estratégia se adaptar a diversas condições luminosas e a essa adaptação dá-se o nome de plasticidade. Essa plasticidade estrutural está associada a uma função compensatória das folhas de sombra à diminuição proporcional da fotossíntese e à diminuição da intensidade luminosa, visto que tais folhas aproveitam melhor a luminosidade, em comparação com aquelas não adaptadas a esse fator (Larcher, 2000). A luz atua de forma significativa e complexa no acúmulo e na variedade dos componentes dos óleos essenciais, uma vez que afeta direta ou indiretamente a produção de biomassa, a proporção de órgãos e as vias biossintéticas destes metabólitos secundários (Oliveira et al., 2007). 
Dessa forma, modificações nos níveis de luminosidade ao qual uma espécie está adaptada podem condicionar diferentes respostas fisiológicas em suas características bioquímicas, anatômicas e de crescimento (Atroch et al., 2001). A luz pode influenciar os níveis e a composição do óleo essencial, dependendo da espécie. Li et al. (1996), trabalhando com tomilho (Thymus vulgaris), observaram que o teor de óleo essencial foi mais alto em plantas cultivadas a 100\% de irradiância. Plantas de erva-cidreira (Lippia alba) submetidas a um nível maior de irradiância (pleno sol) tiveram elevação no teor de óleo essencial (Ventrela e Ming, 2000).

A obtenção de informações que permitam conhecer os efeitos dos tratamentos utilizados nos cultivos das plantas medicinais sobre a estrutura interna dessas plantas é também de fundamental importância, pois existe íntima relação entre os tipos e a organização dos tecidos vegetais e a produção dos diferentes metabólitos (Taiz e Zeiger, 2004).

Assim, o objetivo do presente trabalho foi avaliar a produção de biomassa, óleo essencial e quantidade de tricomas glandulares no cidrão em função de níveis de irradância.

\section{Material e Métodos}

O estudo com L. citriodora foi realizado no Horto Medicinal e no laboratório de Plantas medicinais do Instituto de Ciências Agrárias (ICA) da Universidade Federal de Minas Gerais (UFMG) no município de Montes Claros - MG (650m de altitude, 1640'50,92”S e $43^{\circ} 50$ '22,36”'W). No período de 25 de junho de 2007 até 15 de setembro de 2007. Na cidade de Montes Claros o clima é do tipo tropical semi-úmido, com temperatura média em torno de $25^{\circ} \mathrm{C}$ e com estação seca prolongada (aproximadamente cinco meses por ano com início no inverno).

As mudas foram obtidas por estaquia, originárias da coleção de germoplasma de plantas medicinais do ICA/UFMG. As mesmas foram produzidas em substrato comercial, tipo "plantamax", e, após dois meses, foram transplantadas para vasos de seis litros solo-esterco, sendo utilizada duas mudas por vaso.
Os tratamentos consistiram de níveis de diferentes radiações fotossinteticamente ativa (RFA): a pleno sol (testemunha) e sombreamento progressivo com tela de sombrite que permite a passagem de $25 \%, 50 \%$ e $70 \%$ de luz. A RFA (comprimento de onda entre 400 e 700nm) foi determinada em cada tratamento com fotômetro equipado com sensor de quantum, em dez datas ao longo do cultivo, sempre na parte da manhã, sendo determinada à porcentagem média de RFA em relação à radiação máxima (sem sombreamento com 1954 4 mol.m-2.s-1). Os vasos foram mantidos com umidade próxima à capacidade de campo, sendo irrigados quando necessário. $\mathrm{O}$ experimento foi instalado em delineamento experimental inteiramente casualizado com quatro tratamentos e sete repetições, num total de vinte oito parcelas.

A quantificação dos tricomas glandulares (T) foi realizada antes do florescimento. Foram coletadas três folhas totalmente expandidas do terço médio de cada planta e confeccionadas lâminas histológicas para a contagem dos tricomas. Os tricomas foram contados em triplicata em um campo de $1 \mathrm{~mm}^{2}$ na região mediana das folhas utilizando microscópio binocular.

A colheita foi realizada pela manhã, 81 dias após o plantio. A partir do material coletado foi determinada a massa fresca de raiz (MFR), massa fresca de parte aérea (MFPA), número de flores (NF), massa seca da raiz (MSR), massa seca da parte aérea (MSPA), matéria seca total (MST), razão raiz/parte aérea (RPA), produção de óleo (PO), teor de óleo na matéria fresca (TOF) e teor de óleo na matéria seca (TOS). Em seguida, no laboratório, as plantas foram fragmentadas e armazenadas em freezer para posterior extração de óleo essencial e as raízes foram colocadas em estufa com circulação de ar forçada, à temperatura de $64^{\circ} \mathrm{C}$ até alcançar peso constante.

Os óleos essenciais foram obtidos por hidrodestilação usando-se o aparelho de Clevenger modificado, sendo utilizada toda a parte aérea que foi colocada em balão de vidro e imersa em água destilada até atingir no máximo $2 / 3$ do balão. O processo de extração dos óleos teve a duração de três horas, sendo que, ao final, o óleo foi separado da água por separação liquido-liquido (USP, XXII, 1990). Após extração o material foi levado para estufa, para posterior determinação de sua matéria seca. 
O teor de óleo essencial foi expresso em grama de óleo por grama de matéria seca.

Os dados obtidos nesse estudo foram submetidos à análise de variância, sendo aplicado o teste Tukey de comparação de médias a 5\% de probabilidade. Para a análise, as variáveis, teor de óleo na matéria fresca (TOF), teor de óleo na matéria seca (TOS) e número de flor (NF) foram previamente transformados para $\sqrt{\mathrm{x}+0,5}$.

\section{Resultados e Discussão}

Foram observadas diferenças estatisticamente significativas para a massa fresca da raiz (MFR), massa seca da raiz (MSR), massa fresca da parte aérea (MFPA), massa seca da parte aérea (MSPA), número de flores $(\mathrm{NF})$, matéria seca total (MST), razão raiz/parte aérea (R/PA) e produção de óleo (PO), sendo que teor de óleo na matéria fresca (TOF) e teor de óleo na matéria seca (TOS) não variaram significativamente.

A maior produção de MFR e MSR (Tabela 3) foi observada no tratamento a pleno sol $(47,97 \mathrm{~g})$, sendo a menor média para o sombreamento de $25 \%(16,87 \mathrm{~g})$. Resultados semelhantes foram observados por Ramos et al. (2004) em Amburana cearensis (Allemao) A.C. Smith, onde o tratamento a pleno sol apresentou maior biomassa de raiz e no tratamento com $90 \%$ de sombreamento a menor biomassa. Para MSPA, o tratamento de $25 \%$ foi 2,71 vezes inferior ao tratamento a pleno sol $(34,57 \mathrm{~g})$. Ortega et al. (2006), avaliando o crescimento de mudas de Psidium cattleianum Sabine A., também constataram que plantas a pleno sol possuíam maior massa de matéria seca da parte aérea.

Em relação à matéria seca total a pleno sol observouse maior média do que sob 50 e $25 \%$ de luz. Os resultados obtidos nos sombreamentos de $50 \%$ e $70 \%$ não diferiram entre si e o sombreamento de $25 \%$ apresentou o menor valor, diferindo dos demais concordando com Pinto et al. (2007) no estudo de Aloysia gratissima. Nakazono et al. (2001), que ao estudarem o crescimento inicial de Euterpe edulis, sob diferentes níveis de irradiação, observaram que as plantas a pleno sol apresentaram biomassa de matéria seca total inferior aos demais sombreamentos. Com relação ao NF, os tratamentos a pleno sol e 70\% apresentaram médias superiores aos demais tratamentos, resultado semelhante, para o número de inflorescência, encontrado por Souza et al. (2007), estudando níveis de sombreamento em Lippia sidoides.

A razão raiz/parte aérea apresentou sua maior média para o tratamento de $25 \%$. Resultados semelhantes foram encontrados por Felfili et al. (1999) em Sclerolobium paniculatum.

O teor de óleo (TO) não variou significativamente entre os tratamentos, mas apresentou média com tendência de superioridade para os tratamentos a pleno sol $(0,16)$ e $70 \%$ de luz $(0,11)$. O mesmo foi observado por De Bona et al. (2003) em carqueja (Baccharis trimera) (pleno sol com 1,2 e 70\% com 1,05) e em alfavaquinha (Ocimum selloi Benth.) onde, a pleno sol as folhas apresentaram maior teor de óleo $(1,045)$ que no sombreamento $(1,008)$ (Gonçalves et al., 2003).

Todavia, para a variável produção de óleo as médias dos tratamentos $50 \%$ e $25 \%$ apresentaram valores inferiores ao do pleno sol, mas não diferiram do tratamento de $70 \%$ de luz (Tabela 1). Gil et al. (2003) observaram que clones de cidrão (L. citriodora) provindos de diferentes localizações apresentam diferenças na síntese de óleo essencial e no crescimento de biomassa, o mesmo foi encontrado por Díaz et al. (2007) que, ao compararem a composição química do óleo essencial de cidrão em diferentes regiões da Colômbia, verificaram o fato de que a maior concentração de metabólitos de interesse se dá aos dois meses de idade e antes da floração. De acordo com Stashenko et al. (2003) o cidrão não apresenta problemas de adaptação em outras latitudes e sua parte aérea contém uma concentração de 0,1 a $\%$ de óleo essencial.

Quanto ao número de tricomas glandulares (T) os tratamentos a pleno sol, $70 \%$ e $50 \%$ de luz não apresentaram diferenças significativas entre si (Tabela 2), indicando que quando a intensidade luminosa diminui favorece o decréscimo no número de tricomas, podendo favorecer o decréscimo no teor de óleo essencial, já que os mesmos em sua maioria são armazenados nos tricomas glandulares. 
TABELA 1: Massa fresca de raiz (MFR), massa seca da raiz (MSR), massa fresca da parte aérea (MFPA), massa seca da parte aérea (MSPA), número de flores (NF), matéria seca total (MST), razão raiz/parte aérea (R/PA), produção de óleo (PO), teor de óleo (TO) e quantificação de tricomas glandulares (QT) em cidrão (L. citriodora) cultivado em quatro níveis de radiação fotossinteticamente ativa (RFA) em Montes Claros - MG.

\begin{tabular}{|c|c|c|c|c|c|c|c|c|c|}
\hline \multirow{2}{*}{ Tratamento } & MFR & MSR & MFPA & MSPA & MST & \multirow{2}{*}{ PO } & \multirow{2}{*}{ NF } & \multirow{2}{*}{$\mathbf{R} / \mathbf{P A}$} & \multirow{2}{*}{ TO } \\
\hline & \multicolumn{5}{|c|}{ g. planta ${ }^{-1}$} & & & & \\
\hline $\begin{array}{l}\text { Testemunha } \\
\text { (luz plena) }\end{array}$ & $47,97 \mathrm{a}$ & $21,12 \mathrm{a}$ & $109,14 \mathrm{a}$ & $34,57 \mathrm{a}$ & $55,70 \mathrm{a}$ & $0,15 \mathrm{a}$ & $1,57 \mathrm{a}$ & $0,64 \mathrm{ab}$ & $0,16 \mathrm{a}$ \\
\hline $70 \%$ de luz & $36,07 b$ & $17,35 b$ & $98,71 \mathrm{a}$ & $30,42 \mathrm{ab}$ & $47,78 \mathrm{ab}$ & $0,11 \mathrm{ab}$ & $1,14 \mathrm{a}$ & $0,57 b$ & $0,11 \mathrm{a}$ \\
\hline $50 \%$ de luz & $31,35 b$ & $15,35 b$ & $89,85 \mathrm{a}$ & $24,57 b$ & $39,92 b$ & $0,08 b$ & $0,28 b$ & $0,62 \mathrm{ab}$ & $0,07 \mathrm{a}$ \\
\hline $25 \%$ de luz & $16,87 \mathrm{c}$ & $9,44 \mathrm{c}$ & $52,14 \mathrm{~b}$ & $12,71 \mathrm{c}$ & $22,15 \mathrm{c}$ & $0,07 \mathrm{~b}$ & $0,0 \mathrm{~b}$ & $0,80 \mathrm{a}$ & $0,05 \mathrm{a}$ \\
\hline $\mathbf{F}$ & $1158,24 * *$ & $166,66 * *$ & $4312,32 * *$ & $632,09 * *$ & $3,75 * *$ & $1441,3 * *$ & $0,72 * *$ & $1158,24 * *$ & $0,98 n s$ \\
\hline
\end{tabular}

As médias seguidas de pelo menos uma mesma letra minúscula, na coluna, não diferem significativamente pelo teste de Tukey, a $5 \%$ de probabilidade. ${ }^{* *}$ - significativo a $5 \%$ de probabilidade pelo teste $\mathrm{F}$. ns - não significativo a $5 \%$ de probabilidade pelo teste $\mathrm{F}$.

TABELA 2: Valor médio da variável quantificação de tricomas glandulares $(T)$ em cidrão $(L$. citriodora) cultivado em quatro níveis de radiação fotossinteticamente ativa (RFA) em Montes Claros - MG.

\begin{tabular}{c|c}
\hline Tratamento (\% de luz) & T (tricomas $/ \mathbf{m m}^{2}$ ) \\
\hline Testemunha (luz plena) & $177,45 \mathrm{a}$ \\
$70 \%$ de luz & $182,33 \mathrm{a}$ \\
$50 \%$ de luz & $147,63 \mathrm{a}$ \\
25\% de luz & $48,66 \mathrm{~b}$ \\
\hline
\end{tabular}

As médias seguidas de pelo menos uma mesma letra minúscula, na coluna, não diferem significativamente pelo teste de Tukey, a $5 \%$ de probabilidade. ${ }^{* *}$ - significativo a $5 \%$ de probabilidade pelo teste F.

Rivas (2003) observou que a síntese e acumulação de óleo essencial podem ocorrer em sombreamento e alta iluminação, porém nos tratamentos com sombreamento as folhas ficam maiores, mas com menor concentração de óleo. Pegoraro (2007) observou que no sombreamento em hortelã pimenta os tratamentos com maior intensidade luminosa não interferiram no rendimento de óleo por tricomas. No entanto, ele relata que como a quantidade de área foliar por planta aumentou com maior intensidade luminosa, é possível supor que o rendimento de óleo por planta seja aumentado em virtude do aumento do número de tricomas por planta.

Considerando a produção da espécie para extração de óleo essencial recomenda-se o plantio a pleno sol, pois os resultados demonstraram que o teor de óleo essencial não variou em comparação aos demais tratamentos, a produção de biomassa foi favorecida e a quantidade de tricomas glandulares pode ter favorecido um maior teor de óleo na planta.

\section{Referências}

Atroch, E. M. A. C.; Soares, A. M.; Alvarenga, A. A.; Castro, E. M. 2001. Crescimento, teor de clorofilas, distribuição de biomassa e características anatômicas de plantas jovens de Bauhinia forficata submetidas à diferentes condições de sombreamento. Revista de Ciência Agrotecnológica, 25 (4): 853-862.

Chopra, R. N.; Nayar, S. L.; Chopra, I. C. 1986. Glossário de plantas medicinais da Índia (suplemento including). Conselho da Pesquisa Científica e Industrial, Nova Deli, India, $329 \mathrm{pp}$.

De Bona, C. M.; Biasi, L. A.; Costa, G.; Zanette, F.; Nakashima, T. 2003. Calagem e sombreamento na produção de biomassas e rendimento de óleo essencial em carqueja (Baccharis trimera A.P. de Candolle). Revista Brasileira de Plantas Medicinais, 6 (1): 28-32. 
Díaz, O. L.; Duran, D. C. G.; Martínez, J. R.; Stashenko, E. E. 2007. Estúdio comparativo de la composición química de los aceites esenciales de Aloysia triphylla L'Her Britton cultivadas en diferentes regiones da Colômbia. Scientia et Technica, 13 (33): 351-353.

Felfili, J. M.; Hilgbert, L. F.; Franco, A. C.; Sousa-Silva, J. C.; Resende, A. V.; Nogueira, M. V. P. 1999. Comportamento de plântulas de Sclerolobium paniculatum Vog. var. rubiginosum (Tul.) Benth. sob diferentes níveis de sombreamento, em viveiro. Revista Brasileira de Botânica, 22 (2): 297-301.

Gil,A.; Morvillo, C.; Conde, C. 2003. Aloysia citriodora variabilidad intraespecífica y compromiso entre la acumulación de biomasa y el aceite esencial. II Simpósio Brasileiro de Óleos Essenciais. Diagnóstico e Perspectivas, Campinas, Brasil, p. 21.

Gonçalves, L. A.; Barbosa, L. C. A.; Azevedo, A. A.; Casali, V. W. D.; Nascimento, E. A. 2003. Produção e composição do óleo essencial de alfavaquinha (Ocimum selloi Benth.) em resposta a dois níveis de radiação solar. Revista Brasileira de Plantas Medicinais, 6 (1): 8-14.

Larcher, W. 2000. Ecofisiologia vegetal. Rima, São Carlos, Brasil, $531 \mathrm{pp}$.

Li, Y. L.; Craker, L. E.; Potter, T. 1996. Effect of light level on essential oil production of sage (Salvia officinalis) and thyme (Thymus vulgaris). Acta Horticulturae, 426: 419-427.

Lorenzi, H.; Matos, F. J. A. 2002. Plantas medicinais no Brasil Nativas e exóticas cultivadas. Nova Odessa, Instituto Plantarum, SP, 512pp.

Nakazono, E. M.; Costa, M. C.; Futatsugi, K.; Paulilo, M. T. S. 2001. Crescimento inicial de Euterpe edulis Mart. em diferentes regimes de luz. Revista Brasileira de Botânica, 24 (2): 173-179.

Oliveira, M. I.; Castro, E. M.; Costa, L. C. B.; Pinto, J. E. B. P.; Amaral, T. A. 2007. Crescimento e teor de óleo essencial de plantas jovens de Artemísia vulgaris submetidas a diferentes condições de radiação. Anais do VIII Congresso de Ecologia do Brasil, Caxambu, Brasil, p.3.

Ortega, A. R.; Almeida, L. S.; Maia, N.; Angelo, A. C. 2006. Avaliação do crescimento de mudas de Psidium cattleianum Sabine a diferentes níveis de sombreamento em viveiro. Cerne, 12 (3): 300-308.

Pegoraro, R. L. 2007. Avaliação do crescimento e produção de óleos essenciais em plantas de Mentha $x$ piperita 1 . var. piperita (Lamiaceae) submetidas a diferentes níveis de luz e nutrição. Dissertação de Mestrado, Universidade Federal de Santa Catarina, Brasil, 59pp.
Perecin, M. B.; Bovi, O. A.; Maia, N. B. 2002. Pesquisa com plantas aromáticas, medicinais e corantes: o papel do Instituto Agronômico. O Agronômico, 54 (2): 21-24.

Pinto, J. E. B. P.; Cardoso, J. C. W.; Castro, E. M.; Bertolucci, S. K.; Melo, L. A.; Dousseau, S. 2007. Aspectos morfofisiológicos e conteúdo de óleo essencial de plantas de alfazema-do-Brasil em função de níveis de sombreamento. Horticultura Brasileira, 25 (2): 210-214.

Ramos, K. M. O. Felfili, J. M.; Fagg, C. W.; Sousa-Silva, J. C.; Franco, A. C. 2004. Desenvolvimento inicial e repartição de biomassa de Amburana cearensis (Allemao) A.C. Smith, em diferentes condições de sombreamento. Acta Botânica Brasílica, 18 (2): 351-358.

Rivas, D. A. P. 2003. Arquitectura y modelos de regeneración en plantas medicinales comercializadas en Chile. Pontificia Universidad Católica de Chile, Facultad de Agronomía e Ingeniería Forestal, Santiago, Chile, 53pp.

Simões, C. M. O.; Mentz, L. A.; Schenkel, E. P.; Irgang, B. E.; Stehmann, J. R. 1998. Plantas da medicina popular do Rio Grande do Sul. $5^{\text {a }}$ ed. UFRGS, Porto Alegre, Brasil, 173pp.

Souza, M. F.; Gomes, P. A.; Souza, I. T.; Fonseca, M. M.; Siqueira, C. S.; Figueiredo, L. S.; Martins, E. R. 2007. Influência do sombreamento na produção de Fitomassa e Óleo Essencial em Alecrim-Pimenta (Lippia sidoides Cham.). Revista Brasileira de Biociências, 5 (2): 108-110.

Stashenko, E. E.; Jaramillo, B. E.; Martínez, J. R. 2003. Comparación de la composición química y de la actividad antioxidante in vitro de los metabolitos secundarios volátiles de plantas de la familia Verbenaceae. Revista de La Academia Colombiana de Ciencias Exactas, Físicas y Naturales, 27 (105): 579-598.

Taiz, L.; Zeiger, E. 2004. Fisiologia Vegetal. Artmed, Porto Alegre, Brasil, 719pp.

Teske, M.; Trinttini, A. M. M. 1997. Compêndio de fitoterapia. $3^{\text {a }}$ ed. Herbarium, Paraná, Panamá, 197pp.

Ventrella, M. C.; Ming, L. C. 2000. Produção de matéria seca e óleo essencial em folhas de erva-cidreira sob diferentes níveis de sombreamento e épocas de colheita. Horticultura Brasileira, 18: 972-974.

USP, XXII. 1990. The United States Pharmacopoeia. 22 $2^{\text {th }}$ ed. United States Pharmacopoeial Convention, Rockville, USA, 482pp. 